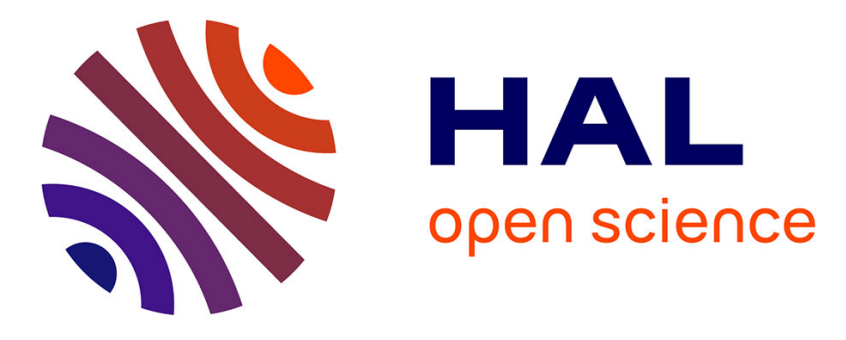

\title{
Veno-Arterial-ECMO in the Intensive Care Unit:From Technical Aspects to Clinical Practice
}

Arthur Le Gall, Arnaud Follin, Bernard Cholley, Jean Mantz, Nadia Aissaoui, Romain Pirracchio

\section{- To cite this version:}

Arthur Le Gall, Arnaud Follin, Bernard Cholley, Jean Mantz, Nadia Aissaoui, et al.. Veno-ArterialECMO in the Intensive Care Unit:From Technical Aspects to Clinical Practice. Anaesthesia Critical Care \& Pain Medicine, 2017, pp.1-43. 10.1016/j.accpm.2017.08.007 . hal-01629078

\section{HAL Id: hal-01629078 https://hal.inria.fr/hal-01629078}

Submitted on 6 Nov 2017

HAL is a multi-disciplinary open access archive for the deposit and dissemination of scientific research documents, whether they are published or not. The documents may come from teaching and research institutions in France or abroad, or from public or private research centers.
L'archive ouverte pluridisciplinaire HAL, est destinée au dépôt et à la diffusion de documents scientifiques de niveau recherche, publiés ou non, émanant des établissements d'enseignement et de recherche français ou étrangers, des laboratoires publics ou privés. 


\section{Veno-Arterial-ECMO in the Intensive Care Unit:}

\section{From Technical Aspects to Clinical Practice}

Arthur Le Gall ${ }^{1,4,5}$, MD. ; Arnaud Follin ${ }^{1,3}$, MD. ; Bernard Cholley ${ }^{1,3}$, MD. PhD. ; Jean Mantz ${ }^{1,3}$, MD. PhD. ; Nadia Aissaoui ${ }^{2,3}$, MD. PhD. ; Romain Pirracchio ${ }^{1,3}$, MD. PhD.

1 - Anesthesiology and Intensive Care Department, European Hospital Georges Pompidou; 2 - Medical Intensive Care Unit, European Hospital Georges Pompidou; 3 - Paris Descartes University, Sorbonne Paris Cité, Paris, France; 4 - INRIA Paris-Saclay University, Palaiseau, France; 5- LMS, Paris-Saclay University, Palaiseau, France

\section{Corresponding author:}

Romain Pirracchio,

Department of Anesthesia and Critical Care Medicine,

Hôpital Européen Georges Pompidou

20 rue Leblanc, 75015 Paris

Tel: +33 (0) 156092513

Email : romain.pirracchio@aphp.fr

Word Count: 4665

Figures : 03, Tables: 01

No conflict of interest to be declared. 
Content

Summary

Introduction

Principles and technical aspects

Vascular access - Peripheral versus Central VA-ECMO ................................... 5

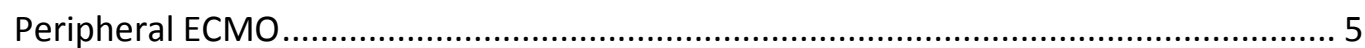

Central ECMO

Gas exchanges determinants during VA-ECMO ................................................ 8

Circulatory support during VA-ECMO

Specific Management during VA-ECMO

Indications

Cardiac Arrest..................................................................................................... 14

Acute Cardiac failure.............................................................................................. 15

Indications to Initiate a VA-ECMO _..................................................................... 18

Weaning strategies

Conclusion

Tables

FigureS

Bibliography

Fundings 


\section{Summary}

3 The use of Veno-Arterial ExtraCorporeal Membrane Oxygenation (VA-ECMO) as a salvage

4 therapy in cardiogenic shock is becoming of current practice. While VA-ECMO is potentially

5 a life-saving technique, results are sometimes mitigated, emphasizing the need for selecting

6 the right indication in the right patient. This relies upon a clear definition of the individual

7 therapeutic project, including the potential for recovery as well as the possible complications

8 associated with VA-ECMO. To maximize the benefits of VA-ECMO, the basics of

9 extracorporeal circulation should be perfectly understood since VA-ECMO can sometimes be

10 detrimental. Hence, to be successful, VA-ECMO should be used by teams with sufficient

11 experience and initiated after a thorough multidisciplinary discussion considering patient's

12 medical history, pathology as well the anticipated evolution of the disease. 


\section{Introduction}

2

3 Veno-Arterial Extra-Corporeal Membrane Oxygenation (VA-ECMO) or Extra-Corporeal Life

4 Support (ECLS) are two terms that designate devices originally created to replace heart and

5 lung functions. Both denominations are synonymous and we will keep the term "VA-ECMO"

6 throughout this review for the sake of consistency. While VA-ECMO was initially dedicated

7 to cardiac surgery (i.e. cardiopulmonary bypass), technical evolutions such as pump

8 miniaturization, better circuit biocompatibility and easier cannulation have enabled this

9 technique to enter the Intensive Care Unit (ICU). VA-ECMO was tested in various indications [1-7]. Nevertheless, because of inconsistent success rates [1-7], significant complications, and high-related costs, it is of paramount importance to accurately identify the patients in whom VA-ECMO may be reasonably initiated.

The goal of this article is to describe some key technical aspects of VA-ECMO, to present a literature overview on the use of VA-ECMO in critically ill patients and ultimately to help the intensivist to identify the appropriate indications for VA-ECMO. 


\section{Principles and technical aspects}

2

3

4

5

6

7

The principle is directly derived from extra corporeal circulation techniques used during cardiac surgery. Venous deoxygenated blood is mechanically suctioned, from a large central vein through a venous cannula, by a centrifugal pump. It is then oxygenated, warmed and restituted into systemic circulation through an arterial cannula. Hence, VA-ECMO is used to assist the heart by insuring part or all the systemic blood flow (Figure 1).

\section{Vascular access - Peripheral versus Central VA-ECMO}

Among VA-ECMO circuits, a distinction has to be made between those inserted centrally or peripherally.

\section{Peripheral ECMO}

The typical configuration for peripheral VA-ECMO involves blood drainage from a femoral venous access and reinfusion through a femoral arterial cannula. With this configuration, the reinfusion cannula generates a retrograde flow up in the aorta that may encounter the anterograde flow generated by the left ventricle [8].

For peripheral VA-ECMO configurations, percutaneous ultrasound guided femoro-femoral access is usually a quick and efficient way of insertion [9], even though it can become more difficult in case of profound arterial hypotension or hemostasis disorders for instance. The alternative is a surgical insertion that allows for a direct visualization of the vessels as well as a simultaneous insertion of the reperfusion cannula (see below) but depends upon the availability of the surgical team.

Whatever the insertion technique chosen, peripheral VA-ECMOs carries specific complications. First, peripheral VA-ECMO may lead to an obstruction of the common femoral artery that can cause lower limb ischemia [10-13]. It is thus advised to place a 
1 reperfusion catheter in the ipsilateral superficial femoral artery [11]. Another drawback of

2 peripheral VA-ECMO is the competition between the retrograde flow generated by the VA-

3 ECMO and the native anterograde flow [8]. This competition may induce or worsen 2 types

4 of complications: 1) LV overload; and 2) Harlequin syndrome.

\section{$5 \quad$ Left Ventricle $(L V)$ overload}

6 Even when the VA-ECMO support is fully covering the cardiac output, there is still blood entering the cardiopulmonary circulation since part of the coronary circulation ends up into the cardiac chambers, including the left atrium or ventricle, through the Thebesian veins [14]. This residual filling of a failing left ventricle (LV) may cause a pulmonary edema especially with peripheral VA-ECMO. In this case, whilst VA-ECMO unloads the right heart, the increase in the LV afterload generated by the assistance itself may overload the LV [15].

Thus, inotropes should be maintained or introduced in case of ventricular dilation or evidence of pulmonary edema. Mean arterial pressure should always be tightly controlled, and adapted to both organ perfusion and cardiac function. In some cases, vasodilators may also be used, in order to adjust the mean arterial pressure.

Additional therapies may be necessary to unload the LV. The use of an Intra-Aortic Balloon Pump (IABP) was reported to be associated with a reduction in the LV afterload $[15,16]$. It may help to restore pulsatile condition, and lower the Pulmonary Artery Occlusion Pressure in VA-ECMO patients $[17,18]$. Nevertheless, although an IABP may improve macrocirculatory parameters without significant complications [19], its benefits remain uncertain [20,21].

In case of refractory pulmonary edema, a LV vent may be added to the extracorporeal circuit. Percutaneous Trans-Aortic, or surgical vent are possible in this context. Recent data suggest that either the percutaneous trans-Aortic devices or the surgical vents may be beneficial to unload the LV in case of pulmonary edema [22-25] and improve survival in this context [26]. 
1 Since there is no argument for a clear benefit of one technique over the other [25,27,28], the

2 choice of a percutaneous or a surgical vent should be based upon the VA-ECMO settings

3 (centrally or peripherally inserted - see below -) and the availability of the surgical team.

4

\section{$\underline{\text { Harlequin Syndrome }}$}

In case of a concomitant respiratory failure, and especially in the cardiac recovery period, the blood flow competition may also cause a Harlequin syndrome [8,29,30]. Indeed, if the residual heart function is able to generate a native perfusion, the interface (or watershed) between the anterograde (native and poorly oxygenated blood) and retrograde (assisted and well oxygenated blood) flows may be located at the level of the supra-aortic trunks. Its clinical expression (cyanosis in the upper part of the body, with subsequent risk of cerebral or myocardial ischemia, constrasting with pink well-perfused lower part of the body, generating this aspect of "Harlequin") results from a selective upper body hypoxia.

It is recommended [31] to monitor oxygen saturation at left hand, while getting blood sample for arterial blood gas analysis on the right hand, in order to detect promptly a discrepancy between right and left arms. Managing a Harlequin syndrome may include: VA-ECMO withdrawal if cardiac recovery is sufficient, increase of the VA-ECMO flow to reduce the relative participation of the native hypoxemic flow to brain perfusion, "centralization", or addition of a partial reinjection cannula into the internal jugular vein (so called veno-arterialvenous ECMO, VAV-ECMO) [32]. If the circulatory support is no longer needed, but respiratory support is still requested, a switch toward a veno-venous ECMO can be considered.

\section{Central ECMO}

Central VA-ECMOs are always inserted surgically. The venous cannula is placed in the right atrium and the arterial cannula in the ascending aorta. The oxygenated blood is injected 
anterogradely in the aorta through the arterial cannula. Thus, with central ECMO there is no competition between with the native heart thereby reducing the risk of LV overload and virtually no risk of Harlequin syndrome.

At the population level, no cannulation site has proven its superiority over the other in terms of outcome or hemodynamic stability [33]. The choice of the best technique essentially depends on the situation (emergent or less emergent VA-ECMO), on the indication and on the risk of complications at the individual level. Central VA-ECMO is typically considered in case of post-cardiopulmonary bypass related heart failure. It needs a surgical team to be inserted and is associated with a higher risk of complications such as mediastinitis or bleeding, as compared with peripheral VA-ECMO [12,33]. Peripheral VA-ECMO, whether inserted surgically or percutaneously, can be implanted faster, but is associated with higher risk of LV overload or Harlequin syndrome. Thus, any emergent indication for cardiorespiratory assistance should typically lead to prefer peripheral insertion while central VA-ECMO can be considered as an alternative to peripheral VA-ECMO in case of refractory pulmonary edema, Harlequin syndrome or limb ischemia occurring downstream the femoral arterial cannula despite reperfusion.

\section{Gas exchanges determinants during VA-ECMO}

VA-ECMO creates a Venous to Arterial shunt, bypassing the native cardiopulmonary circulation. In order to allow for adequate gas exchanges, the VA-ECMO circuit has to provide optimal oxygen delivery and $\mathrm{CO}_{2}$ removal. In the artificial lung (i.e the oxygenator), as well as in the native lungs, blood oxygenation and decarboxylation result from double convective exchanges occurring alongside a semipermeable membrane. Therefore, during VA-ECMO, $\mathrm{PaO}_{2}$ and $\mathrm{PaCO}_{2}$ both depend upon extra-corporeal circulation settings and patient's characteristics. 
1 Indeed, the Cardiac Output (CO) and the Pump Flow Rates (PFR), and more specifically their

2 ratio $(\mathrm{PFR} / \mathrm{CO})$, are both of crucial importance. If the PFR/CO ratio is close to 0 (i.e. the artificial shunt is null), the fraction of oxygenated blood coming from VA-ECMO is negligible and so is the benefit in terms of $\mathrm{PaO}_{2}$. However such a situation should not be encountered since the minimal Pump Flow Rates should never be lower than $1500 \mathrm{ml} / \mathrm{min}$ (risk of circuitry thrombosis, or back flow into the circuitry). If the PFR/CO is close to 1 , the $\mathrm{CO}$ entirely flows through the membrane, and may thus be oxygenated. Nevertheless, at high PFR, the oxygenator performance by itself and more precisely the quality of the membrane may limit oxygen transfer. Indeed, the membrane may be deteriorated by clots, thereby reducing its performance and its lifetime.

Another determinant is the Inspired Oxygen Fraction $\left(\mathrm{FiO}_{2}\right)$. The latter drives the oxygen partial pressure on the VA-ECMO side of the oxygenator, and thus also determines the gradient for oxygen exchange across the membrane. Sweep gas flow which is a major determinant for $\mathrm{CO}_{2}$ removal, has almost no impact on $\mathrm{O}_{2}$ exchanges unless it is turned down close to zero. Indeed, the magnitude of oxygen gradient through the membrane as well as its high permeability for oxygen, explain that oxygen transfer rate is very high.

Blood decarboxylation depends on PFR/CO ratio [34] and sweep gas flow. At membrane entry, $\mathrm{CO}_{2}$ partial pressure is zero and $\mathrm{CO}_{2}$ removing gradient equals $\mathrm{CO}_{2}$ venous partial pressure. As $\mathrm{CO}_{2}$ exchange occurs alongside the membrane, the gradient decreases, thereby reducing $\mathrm{CO}_{2}$ transfer, unless the sweep gas is sufficient to "wash" out the $\mathrm{CO} 2$ accumulated on the VA-ECMO side of the membrane.

\section{Circulatory support during VA-ECMO}

VA-ECMO is used to restore adequate systemic perfusion. Pump flow depends on the size of the vascular accesses, venous circuit resistance, and the pump itself. 
1 For a given Pump Flow Rate, the size of the venous cannula is a major determinant of the

2 inflow. Indeed, pump preload depends on the resistance (or the size) of the venous cannula

3 and on the blood volume in the inferior vena cava and the right atrium. The position of the

4 venous cannula is optimal when the tip is located in the right atrium. When positioned in the

5 inferior or the superior vena cava, the risk of venous collapse is more important.

6 Pump rotation speed is an important determinant of the flow rate and of the pressure gradient.

7 Modern VA-ECMO machines use preferentially centrifugal pumps, which allow for high

8 rotation speed and flow rate with a lower risk of hemolysis. Increasing pump rotation speed

9 increases the flow rate (and decreases the right atrial pressure [35]), unless the suction generated precipitates a transient venous or atrial collapse (Kicking lines) (Figure 2). In such a situation, one must decrease pump rotation speed and/or administer intravascular fluids in order to restore venous/atrial transmural pressure. In addition, to avoid complications such as hemolysis, the maximum theoretical pressure generated by the pump should not exceed -300 mmHg on the venous side, and $+400 \mathrm{mmHg}$ on the arterial side [31].

The impact of the size of the arterial cannula is less important as the pump easily overcomes the resulting afterload. Nevertheless, a too small arterial cannula may cause hemolysis, alter the performance of the pump and limits the flow. Similarly, mean arterial pressure should be tightly controlled in order to limit the increase in afterload and avoid deleterious consequences (see "Specific Management section"). 


\section{Specific Management during VA-ECMO}

2

3

4 5

While non-specific ICU care should be provided during VA-ECMO management, careful attention should be paid on VA-ECMO and ventilator settings as well as anticoagulation therapy.

\section{ECMO management}

Modifying pump flow rates can induce substantial alteration in hematosis or worsen a preexisting cardio-respiratory insufficiency. Therefore, daily ICU care should be provided with great caution. For instance, a simple patient mobilization can cause accidental decannulation, with catastrophic consequences. VA-ECMO could also prevent from appropriately positioning the patient. During patients' positioning it is of paramount importance to carefully verify the cannula, in order to prevent any extracorporeal circulation mobilization or soft tissue alteration. Semi-recombinant position may be difficult with a peripheral VA-ECMO, while central VA-ECMO is not compatible with prone positioning. Prone positioning has been described during peripheral Veno-Venous-ECMO in case of refractory Acute Respiratory Distress Syndrome (ARDS), as described by Otterspoor [36], Kimmoun [37] and Kipping [38]; however, in peripheral VA-ECMO, the risks of kinking of the reperfusion line or accidental withdrawal of the arterial cannula justify that in case of refractory ARDS while on VA-ECMO, a safer alternative to prone positioning can be the addition of a reinjection cannula into the right internal jugular vein (Veno-Arterial-Venous ECMO).

Finally, out-of-ICU exams are also more difficult in patients under ECMO. Double pliers must always be readily available to interrupt quickly the extracorporeal circulation. A manual wheel should always be present to replace the pump in case of outage or dysfunction. The 
membrane should be checked daily, particularly for clots formation (dark red deposit on the membrane). If requested, blood gases can be performed before and after the membrane to evaluate its performance. When blood gases are performed after the membrane, oxygen partial pressure should be greater than $200 \mathrm{mmHg}$. Arterial and Venous cannulas should also be carefully screened. There should be a substantial color difference between dark venous blood and red arterial blood. Non-cyclic oscillations of the circuit associated with decrease in the blood flow, should prompt the team to check the inflow pressure and take the appropriate decisions (decrease Pump Flow Rate, administer fluids, etc). Daily examination of cannulation sitesis also mandated, tracking for bleeding or infection. In case of peripheral ECMO, clinical and Doppler examination of the peripheral pulse should be part of the nurse surveillance, in order to promptly identify any lower limb ischemia.

Ventilator Settings

Ventilator settings should be adapted, in order to avoid ventilator-induced lung injury. Positive pressure ventilation may decrease left and increase right ventricular afterload. This can be either beneficial or detrimental depending on the global cardiac function. For instance, positive pressure ventilation may improve a pulmonary edema on the one hand, while worsening a right heart failure on the other hand. It is proposed to use a protective ventilation strategy with a Tidal Volume of 6 to $8 \mathrm{ml} / \mathrm{kg}$ of ideal body weight, with a maximum PEEP of $10 \mathrm{cmH} 2 \mathrm{O}$ and/or a plateau pressure of $20-25 \mathrm{cmH} 2 \mathrm{O}$, and to adjust the latter settings to the cardiorespiratory function [39]. The recent ELSO guidelines recommend the use of the smallest possible volume and pressure, in order to allow lung rest and recovery [31].

Anticoagulation

Anticoagulation therapy should also be used, except in presence of a specific bleeding risk. Potentially life threatening bleeding events are the most frequent complication during VAECMO [40]. The extracorporeal circuit by itself induces an activation of the inflammatory 
and the coagulation pathways. This, in turn, favor bleeding or clotting complications such as stroke or pulmonary embolism $[41,42]$.

In a study reporting 405 patients under VA-ECMO, the bleeding rate was $31 \%$ [42]. In a recent study, Aubron et al. [40] reviewed the complications of veno-venous and veno-arterial ECMO, and evaluated their impact on mortality. Bleeding was the most frequent adverse event $(27 \%)$, regardless of the type of ECMO. Moreover, the total number of transfused packed red blood cells was an independent predictor of death during VA-ECMO.

On the other hand, avoiding anticoagulation could lead to thrombotic events including stroke. Indeed, clots in the extracorporeal circuit could lead to scatter emboli into the intracranial circulation. On addition, insertion of the arterial cannula into the aorta may damage an atherosclerotic intima, potentially resulting in emboli and multifocal cerebral infarctions. In Hemmila et al. study [42], 5.5\% of the patients on VA-ECMO had ischemic neurological adverse events. When a CT scan was performed systematically, Lindegran et al. [41] reported a $45 \%$ rate of intracranial hemorrhage or infarction. Consistently, Mateen et al. [43] evaluated 42 patients under VA-ECMO, and observed neurological events in 50\% of them. However, in the latter study, VA-ECMO indication was refractory cardiac arrest in $16 \%$ of the patients, a condition highly prone to neurologic complication.

Consequently, anticoagulation is necessary but has to be managed carefully during VAECMO. Generalized use of heparine-coated circuit allows for low dose intravenous heparinization with a TCA ratio target around 1.5 [31]. This is especially possible if the pump rotation speed is high enough as the risk for clotting formation is maximal when the pump flow rate is below $1500 \mathrm{ml} / \mathrm{min}$. 
Infections and other Complications

Aubron et al. [40] reported a high incidence of bloodstream infection (13\% for va- and vvVA-ECMO). Hemmila et al. [42] reported a global infection rate of 38\%. Consistently, a recent meta-analysis including 1,866 patients from 20 studies [44] confirmed the high infection rate under VA-ECMO (30 [20 - 44]\%).

Figure 3, using results of [44], summarizes the rates and the types of complication occurring during VA-ECMO for acute cardio-respiratory failure.

\section{Indications}

The main indication for VA-ECMO is cardiogenic shock resulting from acute myocardial infarction, fulminant myocarditis, acute decompensation of severe chronic heart failure, drug intoxication, hypothermia or intractable arrhythmia. VA-ECMO is also used in some specific situations such as post-cardiotomy cardiac failure or cardiac arrest requiring cardiopulmonary resuscitation. Furthermore, VA-ECMO is proposed for patients with pulmonary embolism, sepsis-associated cardiomyopathy and pulmonary hypertension.

A recent meta-analysis pooled 23 studies $(n=1,199)$ in which VA-ECMO was initiated to treat cardiogenic shock or refractory cardiac arrest. Long-term mortality was reported in 16 studies and overall one-year survival rate was $54.9 \%$ [45].

\section{Cardiac Arrest}

Over the past decade, there has been a growing interest for VA-ECMO in out-of-hospital refractory cardiac arrest. However, the benefit of VA-ECMO is apparently higher in patients with intra-hospital cardiac arrest $[1,46-50]$. This is confirmed in a recent observational propensity-matched study [51] including 320 VA-ECMO for cardiac arrest. Nevertheless, when reducing time to implantation, by implementing pre-hospital ExtraCorporeal Cardio- 
1 Pulmonary Resuscitation (eCPR), Lamhaut et al. found no difference in mortality between in-

2 and out- of hospital cardiac arrest patients, resuscitated with VA-ECMO [52]. Cardiac arrest caused by hypothermia or poisoning have better outcomes than cardiac arrest due to other reasons [2,53-56]. The French council for cardio-pulmonary resuscitation as well as the French society of Anesthesiology and Intensive Care Medicine have limited the indications for VA-ECMO initiation in refractory cardiac arrest to "reasonable" low flow durations (< $100 \mathrm{~min})$, and to cardiac arrests resulting from poisoning or with deep hypothermia $\left(<32^{\circ} \mathrm{C}\right)$ [57]. North American guidelines still do not recommend VA-ECMO in this indication [58].

VA-ECMO has also been used for Post Cardiac Arrest syndrome (PCAS), i.e., patients suffering from a profound cardiogenic shock after return of spontaneous circulation. However, with or without VA-ECMO, mortality reaches 72 to $80 \%$ in this indication $[59,60]$.

\section{Acute Cardiac failure}

Acute Coronary Syndrome (ACS)

Even if European and American guidelines recommend VA-ECMO use in case of ACS leading to heart failure refractory to medical treatment, with IIa and IIb proof levels respectively $[61,62]$, to our knowledge, no randomized study has ever reported any benefit of VA-ECMO as compared to medical treatment alone. These guidelines are only supported by results from observational series [3,63-65]. Indeed, a historical case-control study published in 2010 reported a benefit of VA-ECMO on 30-day survival (OR $=0.22$; 95\%CI [0.060.80] ) in 71 patients with profound cardiogenic shock and acute coronary syndrome [65]. Mortality in the VA-ECMO group was $31.9 \%$. In a study on 98 patients, Sakamoto et al. [3] reported a much higher mortality rate $(67 \%)$. However, the latter study included patients on VA-ECMO for both cardiogenic shock and refractory cardiac arrest. In addition, VA-ECMO- 
1 related complications were frequent in this population, and this was associated with a worst

2 prognosis $(\mathrm{OR}=4.72 ; 95 \%$ CI $[1.39-16.1] ; \mathrm{p}=0.013)$. In an attempt to better identify the

3 patients who benefit from VA-ECMO, Muller et al. identified 7 prognostic factors (age > 60,

4 female sex, body mass index $>25 \mathrm{~kg} / \mathrm{m}^{2}$, Glasgow coma score $<6$, creatinine $>150 \mu \mathrm{mol} / \mathrm{L}$,

5 lactate $>2, \mathrm{mmol} / \mathrm{L}$, and prothrombin activity $<50 \%$ ) in 138 patients under VA-ECMO for

6 Acute Myocardial Infarction [66]. These factors entered into the ENCOURAGE score

7 allowed to predict hospital mortality with an AUC of $0.84,95 \%$ CI [0.77-0.91]

\section{Fulminant Myocarditis}

Fulminant myocarditis or intoxications with cardio-depressant agents are two of the best examples of a bridge to recovery situations. In this pathology, myocardial depression is usually transient and VA-ECMO is used to wait for heart function recovery. VA-ECMO has thus been used with good results and several studies reported survival rates as high as $60-70 \%$ [4,67]. VA-ECMO was shown to improve the outcome in this context $[4,68]$.

\section{Septic Cardiomyopathy}

Myocardial depression is a well-recognized consequence of severe septic shock. Septic cardiomyopathy was reported in up to $60 \%$ of septic shocks [69]. Because this myocardial depression is potentially fully reversible, VA-ECMO was proposed with survival rate from observational series ranging from 21 to $85 \%$ [5,70,71]. However, the level of evidence is still too low to recommend VA-ECMO in this situation.

\section{Post cardiotomy cardiogenic shock}

Postcardiotomy cardiogenic shock occurs in approximately $1 \%$ of the patients after cardiac surgery. In such cases, VA-ECMO may be used as a bridge-to-recovery. However, survival rates in this indication are inconsistent, ranging from 24 to $39 \%[6,72]$. 
Primary graft dysfunction (PGD) after transplantation

Primary graft failure is the first cause of early mortality after heart, lung, and heart-lung transplantation. Data from the International Society for Heart Lung Transplantation (ISHLT) Transplant Registry show $66 \%, 24.7 \%$ and $27 \%$ mortality rates attributable to primary graft dysfunction, during the first 30 days following heart, lung and heart-lung transplantation, respectively [73-75]. The ISHLT states that mechanical support is the only viable therapeutic option in this context. Indeed, VA-ECMO can improve survival rates (as high as 82\%) of patients with graft dysfunction following lung [76] or heart $[7,77,78]$ transplantation.

\section{Bridge to Destination Therapy}

Destination therapies may be considered for end-stage heart failures. They include either heart transplantation or long term Left Ventricular Assist Devices (LVAD). As for lung transplantation, acute decompensation of an end-stage heart failure is associated with a worse prognosis. In this context, VA-ECMO has been proposed to allow recovery from multiple organ failure. In 1999, Pagani et al. [79] reported the feasibility of VA-ECMO as a bridge to destination therapy. The overall survival for patients bridged using VA-ECMO either to LVAD or to transplantation was of $43 \%$. After successful VA-ECMO initiation, survival rates reached $71 \%$ at one year. Further studies have reported survival rates ranging from $50 \%$ to $73 \%$ [80] depending on whether the VA-ECMO was used as a bridge to LVAD (50\%) or to transplantation (73\%). "Bridge to bridge" VA-ECMO has also been reported: VA-ECMO used as a bridge to LVAD, the latter being used as a bridge to transplantation [81]. In this study, the use of VA-ECMO prior to LVAD did not affect mortality at 3 years (13\% vs. $23 \%$ ) or the duration of LVAD assistance (292 [153-448] vs. 311 [175-594] days). Analyses based on the Interagency Registry for Mechanically Assisted Circulatory Support (INTERMACS) registry including approximately 15,000 patients showed that even if VA-ECMO improves the survival rate of patients during decompensation of end-stage diseases, it is a strong 
predictor of poor outcome. Better results are observed when a LVAD is implanted in patients with a stable condition [82-84].

\section{Indications to Initiate a VA-ECMO}

Because the risks associated with the technique are high, a thorough discussion about the best global therapeutic plan is mandatory, including: 1) the choice of the most appropriate cannulation site and type of assistance, 2) anticipation of the potential complications, and 3) of the weaning strategy. Thus, it is crucial to define whether the VA-ECMO is indicated as a bridge to recovery, to transplantation, or as a bridge to destination therapy $[31,85]$.

A "Bridge to recovery" is an assistance initiated to wait for the recovery of a reversible life threatening condition. Typical examples are acute cardiorespiratory failure resulting from acute myocarditis, intoxication with cardiac depressant agents, or coronary syndrome with cardiogenic shock. Prior to inserting the VA-ECMO, the physicians hope that the condition is reversible and that the failing organ will recover after a brief period of support. In the absence of potential reversibility and if none of the alternative support (transplantation or long-term assist device) is deemed feasible, VA-ECMO should not be implanted.

VA-ECMO may be used as a "bridge to transplantation" when the failing organ no longer permits survival and needs to be supported. In this context, VA-ECMO may also allow for the recovery of organ dysfunction such as renal or liver failure or for an appropriate neurological evaluation after withdrawal of the sedation medications.

In the "bridge to destination therapy", VA-ECMO is used to support the heart while waiting for the possibility to implant a long-term mechanical assist device. This is indicated for end stage heart failure, when the patient is temporarily or definitely contraindicated to transplantation. 
1 In the « Bridge to Bridge » strategy, VA-ECMO is implanted as a bridge to Left Ventricular

2 Assist Device that is a more sustainable therapy allowing the patient to be discharged from 3 the ICU, while waiting for a graft. 


\section{Weaning strategies}

After VA-ECMO insertion, daily cardiorespiratory evaluation should be performed to consider VA-ECMO weaning. Indeed, since this assistance carries complications, it is wise to consider withdrawing the VA-ECMO as soon as possible. The evaluation should answers the following questions : i- Has the cardiac function recovered ? ; ii- Has the respiratory function recovered ? ; iii- Could a favorable evolution be predicted ? ; iv- Could further cardiopulmonary aggression be predicted (open heart surgery for example) ? ; v- Will a removal of the assistance be well tolerated?

\section{Weaning Eligibility}

Weaning from VA-ECMO should usually not be attempted within the first 48 hours, since renal and/or hepatic function should recover first. In addition, the etiology of cardiocirculatory dysfunction must be compatible with myocardial recovery. Substantial myocardial recovery can be expected for acute myocarditis, acute myocardial infarction, post-cardiotomy cardiogenic shock or drug intoxication. On the contrary, in most cases, patients with end-stage cardiac disease cannot be taken off VA-ECMO unless for transplantation or insertion of a long-term assist device.

To be eligible for VA-ECMO weaning, patients under VA-ECMO should be deemed hemodynamically stable: mean arterial pressure (MAP) of $>60 \mathrm{mmHg}$ under low doses of vasopressors and a presence of a pulsatile arterial waveform maintained for at least 24 hours.

Weaning Trial

The weaning trial relies on a thorough clinical and echocardiographic examination. The goal is to assess whether the patient would tolerate to be separated from the VA-ECMO on both respiratory and hemodynamic standpoints. To do so, the VA-ECMO blood flow should be decreased progressively to a minimum of $1 \mathrm{~L} / \mathrm{min}$ for at least $15 \mathrm{~min}$ and the sweep gas flow 
1 rate reduced to $1 \mathrm{~L} /$ minute, with a $\mathrm{FiO} 2$ on the VA-ECMO at $21 \%$. If the MAP drops

2 significantly and is constantly $\leq 60 \mathrm{mmHg}$ during the trial, the VA-ECMO flow rate must be 3 returned to $100 \%$ of the initial flow rate and the trial must be stopped. Echocardiography 4 evaluation relies on the variables assessing LV systolic function (Left Ventricular Ejection 5 Fraction - LVEF - and lateral mitral annulus peak systolic velocity), LV flow (aortic velocity6 time integral) and right ventricular diameters and function index (Tricuspid Annular Plane 7 Systolic Excursion - TAPSE). The latter right ventricular function indicators are nevertheless 8 nonconsensual.

9 The oxygen fraction delivered by the extracorporeal circuit should be turned down to $21 \%$ and the one delivered by the ventilator should be less than $60 \%$. The resulting $\mathrm{PaO} 2 / \mathrm{FiO} 2$ ratio should not be lower than 200 .

In summary, VA-ECMO removal can be considered if the patient does not have end-stage cardiac disease, tolerates well the weaning trial, and has a LVEF $\geq 20-25 \%$, an aortic velocity-time integral $\geq 12 \mathrm{~cm}$ and a lateral mitral annulus peak systolic velocity $\geq 6 \mathrm{~cm} / \mathrm{s}$ under minimal VA-ECMO support [86,87] . 


\section{Conclusion}

3 VA-ECMO is an extracorporeal technique that may support cardiorespiratory functions.

4 Because this technique has substantially improved over time, VA-ECMO use is no longer

5 restricted to the operating room and has spread to intensive care units. However, VA-ECMO-

6 related complications are potentially life threatening. Therefore, before starting a VA-ECMO

7 program, it is mandatory to provide to the ICU staff a good understanding and practice of the

8 technical aspects, including insertion of vascular accesses under cardiopulmonary

9 resuscitation. In order to maximize the chances of success, it is of paramount importance to

10 select carefully the patients who can benefit from VA-ECMO and to be able to have multi-

11 disciplinary discussions (involving intensivists, cardiac surgeons and cardiologists) about i)

12 VA-ECMO indications, ii) chances of recovery, iii) the overall plan of care and iv) the

13 appropriate VA-ECMO technique. Hence, the decision to initiate a VA-ECMO and the choice

14 of the best method is best taken by a team of experienced physicians potentially associating

15 intensivists, cardiologists and cardiac surgeons. 


\section{Tables}

2

3 Table 1: Summary of studies per VA-ECMO indication

\begin{tabular}{|c|c|c|c|c|c|c|}
\hline & & & & $\begin{array}{l}\text { VA- } \\
\text { ECMO }\end{array}$ & & \\
\hline Authors & Year & Type & $\begin{array}{l}\text { Cohort } \\
\text { Size }\end{array}$ & $\begin{array}{l}\text { Sample } \\
\text { size }\end{array}$ & Mortality & $\begin{array}{l}\text { Favouring } \\
\text { treatment }\end{array}$ \\
\hline
\end{tabular}

\section{Acute Coronary Syndrome}

\begin{tabular}{|c|c|c|c|c|c|c|}
\hline Fujimoto K [64] & 2001 & $\begin{array}{l}\text { Retrospective, } \\
\text { Observational }\end{array}$ & & $9 \mathrm{pts}$ & $56 \%$ & Not Given \\
\hline Chen JS [63] & 2006 & Prospective, Observational & & 36 pts & $33 \%$ & Not Given \\
\hline Sheu JJ [65] & 2010 & $\begin{array}{l}\text { Retrospective, } \\
\text { Observational }\end{array}$ & $71 \mathrm{pts}$ & $46 \mathrm{pts}$ & $72 \%$ & No \\
\hline
\end{tabular}

\section{Cardiac Arrest}

\begin{tabular}{|c|c|c|c|c|c|c|}
\hline Chen YS [88] & 2003 & $\begin{array}{l}\text { Retrospective, } \\
\text { Observational }\end{array}$ & & 57 pts & $68 \%$ & Not Given \\
\hline Sung K [89] & 2006 & $\begin{array}{l}\text { Retrospective, } \\
\text { Observational }\end{array}$ & & 22 pts & $54 \%$ & Not Given \\
\hline Megarbane B [2] & 2007 & Prospective, Observational & & 17 pts & $86 \%$ & Not Given \\
\hline Ruttmann E [90] & 2007 & $\begin{array}{l}\text { Retrospective, } \\
\text { Observational }\end{array}$ & $59 \mathrm{pts}$ & 25 pts & $72 \%$ & Not Given \\
\hline Chen YS [1] & 2008 & Propensity Matched & 172 pts & $46 \mathrm{pts}$ & $67 \%$ & No \\
\hline Chen YS [91] & 2008 & $\begin{array}{l}\text { Retrospective, } \\
\text { Observational }\end{array}$ & & $135 \mathrm{pts}$ & $66 \%$ & Not Given \\
\hline Lin JW [48] & 2010 & Propensity Matched & $118 \mathrm{pts}$ & $27 \mathrm{pts}$ & $71 \%$ & No \\
\hline Le Guen M[92] & 2011 & Prospective, Observational & & 59 pts & $96 \%$ & Not Given \\
\hline Liu Y [93] & 2011 & $\begin{array}{l}\text { Retrospective, } \\
\text { Observational }\end{array}$ & & 11 pts & $64 \%$ & Not Given \\
\hline Shin TG [94] & 2011 & Propensity Matched & 406 pts & 60 pts & $68 \%$ & Yes \\
\hline Avalli L [46] & 2012 & $\begin{array}{l}\text { Retrospective, } \\
\text { Observational }\end{array}$ & & 42 pts & $74 \%$ & Not Given \\
\hline Haneya A [95] & 2012 & $\begin{array}{l}\text { Retrospective, } \\
\text { Observational }\end{array}$ & & 85 pts & $66 \%$ & Not Given \\
\hline Sakamoto S [3] & 2012 & $\begin{array}{l}\text { Retrospective, } \\
\text { Observational }\end{array}$ & & 64 pts & $72 \%$ & Not Given \\
\hline Wu MY [96] & 2012 & $\begin{array}{l}\text { Retrospective, } \\
\text { Observational }\end{array}$ & & 40 pts & $65 \%$ & Not Given \\
\hline Leick J [97] & 2013 & $\begin{array}{l}\text { Retrospective, } \\
\text { Observational }\end{array}$ & & $28 \mathrm{pts}$ & $61 \%$ & Not Given \\
\hline Maekawa K [98] & 2013 & Propensity Matched & 162 pts & 24 pts & $69 \%$ & Yes \\
\hline Schopka S [50] & 2013 & $\begin{array}{l}\text { Retrospective, } \\
\text { Observational }\end{array}$ & & 103 pts & $72 \%$ & Not Given \\
\hline Chou TH [47] & 2014 & $\begin{array}{l}\text { Retrospective, } \\
\text { Observational }\end{array}$ & 66 pts & 43 pts & $65 \%$ & No \\
\hline Johnson NJ [99] & 2014 & Prospective, Observational & & $26 \mathrm{pts}$ & $85 \%$ & Not Given \\
\hline
\end{tabular}




\begin{tabular}{|c|c|c|c|c|c|c|}
\hline Kim SJ [100] & 2014 & Propensity Matched & 499 pts & 52 pts & $85 \%$ & No \\
\hline Park SB [49] & 2014 & $\begin{array}{l}\text { Retrospective, } \\
\text { Observational }\end{array}$ & & 152 pts & $68 \%$ & Not Given \\
\hline Sakamoto T [101] & 2014 & Prospective, Observational & $454 \mathrm{pts}$ & $260 \mathrm{pts}$ & $88 \%$ & Yes \\
\hline Sawamoto K [53] & 2014 & $\begin{array}{l}\text { Retrospective, } \\
\text { Observational }\end{array}$ & & $26 \mathrm{pts}$ & $62 \%$ & Not Given \\
\hline Wang CH [102] & 2014 & Prospective, Observational & & $230 \mathrm{pts}$ & $68 \%$ & Not Given \\
\hline Han SJ [103] & 2015 & $\begin{array}{l}\text { Retrospective, } \\
\text { Observational }\end{array}$ & & $37 \mathrm{pts}$ & $81 \%$ & Not Given \\
\hline Choi DS [51] & 2016 & Propensity Matched & $\begin{array}{l}36227 \\
\text { pts }\end{array}$ & 320 pts & $82 \%$ & No \\
\hline $\begin{array}{l}\text { De Chambrun MP } \\
\text { [59] }\end{array}$ & 2016 & $\begin{array}{l}\text { Retrospective, } \\
\text { Observational }\end{array}$ & & 94 pts & $73 \%$ & Not Given \\
\hline Bougouin W [60] & 2017 & $\begin{array}{l}\text { Retrospective, } \\
\text { Observational }\end{array}$ & & 52 pts & $73 \%$ & No \\
\hline Lamhaut L [52] & 2017 & Prospective, Observational & $156 \mathrm{pts}$ & 156 pts & $87 \%$ & Not Given \\
\hline
\end{tabular}

\section{Fulminant Myocarditis}

$\begin{array}{llllll}\text { Maejima Y [68] } & 2004 & \begin{array}{l}\text { Retrospective, } \\ \text { Observational }\end{array} & 8 \text { pts } & 25 \% & \text { Not Given } \\ \text { Rajagopal SK [67] } & 2010 \begin{array}{l}\text { Retrospective, } \\ \text { Observational }\end{array} & 255 \text { pts } & 39 \% & \text { Not Given } \\ \text { Mirabel M [4] } & 2011 \begin{array}{l}\text { Retrospective, } \\ \text { Observational }\end{array} & 41 \text { pts } & 34 \% & \text { Not Given }\end{array}$

\section{Septic Myocarditis}

\begin{tabular}{|c|c|c|c|c|c|}
\hline Bréchot N [5] & 2013 & $\begin{array}{l}\text { Retrospective, } \\
\text { Observational }\end{array}$ & $14 \mathrm{pts}$ & $39 \%$ & Not Given \\
\hline Huang CTH [104] & 2013 & $\begin{array}{l}\text { Retrospective, } \\
\text { Observational }\end{array}$ & $52 \mathrm{pts}$ & $85 \%$ & Not Given \\
\hline Park TK [71] & 2015 & $\begin{array}{l}\text { Retrospective, } \\
\text { Observational }\end{array}$ & 32 pts & $81 \%$ & Not Given \\
\hline
\end{tabular}

\section{Post-Cardiotomy}

$\begin{array}{llllll}\text { Doll N [6] } & 2004 & \text { Prospective, Observational } & 219 \text { pts } & 76 \% & \text { Not Given } \\ \text { Rastan AL [72] } & 2009 & \text { Prospective, Observational } & 517 \text { pts } & 75 \% & \text { Not Given } \\ \text { Ma P [15] } & 2014 & \begin{array}{l}\text { Retrospective, } \\ \text { Observational }\end{array} & 54 \text { pts } & 61 \% & \text { Not Given }\end{array}$

\section{Primary Graft Dysfunction}

\begin{tabular}{|c|c|c|c|c|c|c|}
\hline Mihaljevic T [77] & 2010 & Prospective, Observational & & $53 \mathrm{pts}$ & $57 \%$ & Not Given \\
\hline Listijono DR [7] & 2011 & $\begin{array}{l}\text { Retrospective, } \\
\text { Observational }\end{array}$ & 124 pts & $17 \mathrm{pts}$ & $18 \%$ & No \\
\hline Stehlik J [73] & 2011 & $\begin{array}{l}\text { Retrospective, } \\
\text { Observational }\end{array}$ & $\begin{array}{l}10271 \\
\text { pts }\end{array}$ & 180 pts & $\mathrm{RR}=3,32$ & No \\
\hline Hartwig MG [76] & 2012 & Prospective, Observational & & $28 \mathrm{pts}$ & $18 \%$ & Not Given \\
\hline Lima EB [78] & 2015 & Prospective, Observational & & $11 \mathrm{pts}$ & $67 \%$ & Not Given \\
\hline
\end{tabular}

\section{Bridge to Destination Therapy}

$\begin{array}{lllll}\text { Pagani FD [79] } 1999 \text { Retrospective, } & 14 \text { pts } & 50 \% & \text { No }\end{array}$




$\begin{array}{lrlllll}\text { Chung [80] } & 2009 & \begin{array}{l}\text { Observational } \\ \text { Retrospective, } \\ \text { Observational }\end{array} & & 31 \text { pts } & 39 \% & \text { Not Given } \\ \text { Marasco SF [81] } & 2015 & \begin{array}{l}\text { Retrospective, } \\ \text { Observational }\end{array} & 58 \text { pts } & 23 \text { pts } & 13 \% & \text { Not Given }\end{array}$

1 pts : patients; RR : Relative Risk 


\section{Figures}

3 Figure 1: Schematic representation of cannulation ways for implantation of peripheral and 4 central VA-ECMO. A - Centrally inserted veno-arterial ECMO ; B - Peripherally inserted 5 veno-arterial ECMO

Figure 2: Relationship Between Transmural Pressure (Ptm), Venous to Pump Pressure Gradient (Pp-v), and Venous Return Curve.

9 Black arrows represent the strength and the direction of the forces inside the vein. Blue arrows represent the net forces applied to the wall of the vein The Venous Gradient (VG) is the difference between the Pressure in the venous system ( $\mathrm{Pv})$ and the pressure in the pump (Pp): VG $=\mathrm{Pv}-\mathrm{Pp}$. The Ptm is the difference between the Pressure inside (Pin) and outside (Pout) the vein: Ptm = Pin - Pout. The stronger the Pp-v, the higher the flow, until the critical point where the Pv exceeds the Ptm and leads the vein to collapse. 1) Decreasing the pump speed will decrease the VG and in turn will allow the blood to flow and/or 2) Giving fluid can increase the Pv and so the Ptm and can in turn allows the blood to flow

Figure 3: Main complications reported during circulatory support with veno-arterial ECMO. Barplot realized using data obtained from meta-analysis given in [44]. Surgical Control of bleeding : Reintervention for bleeding at the insertion site. Haemorrhage : Bleeding complication others than insertion site (Gastro-Intestinal bleeding for example) 


\section{Bibliography}

[1] Chen Y-S, Lin J-W, Yu H-Y, Ko W-J, Jerng J-S, Chang W-T, et al. Cardiopulmonary resuscitation with assisted extracorporeal life-support versus conventional cardiopulmonary resuscitation in adults with in-hospital cardiac arrest: an observational study and propensity analysis. The Lancet 2008;372:554-561.

[2] Mégarbane B, Leprince $P$, Deye N, Résière $D$, Guerrier $G$, Rettab $S$, et al. Emergency feasibility in medical intensive care unit of extracorporeal life support for refractory cardiac arrest. Intensive Care Med 2007;33:758-64. doi:10.1007/s00134-007-0568-4.

[3] Sakamoto S, Taniguchi N, Nakajima S, Takahashi A. Extracorporeal Life Support for Cardiogenic Shock or Cardiac Arrest Due to Acute Coronary Syndrome. Ann Thorac Surg 2012;94:1-7. doi:10.1016/j.athoracsur.2012.01.032.

[4] Mirabel M, Luyt C-E, Leprince P, Trouillet J-L, Léger P, Pavie A, et al. Outcomes, long-term quality of life, and psychologic assessment of fulminant myocarditis patients rescued by mechanical circulatory support*: Crit Care Med 2011;39:1029-35. doi:10.1097/CCM.0b013e31820ead45.

[5] Bréchot $N$, Luyt $C-E$, Schmidt $M$, Leprince $P$, Trouillet J-L, Léger $P$, et al. Venoarterial Extracorporeal Membrane Oxygenation Support for Refractory Cardiovascular Dysfunction During Severe Bacterial Septic Shock*: Crit Care Med 2013;41:1616-26. doi:10.1097/CCM.0b013e31828a2370.

[6] Doll N, Kiaii B, Borger M, Bucerius J, Krämer K, Schmitt DV, et al. Five-Year results of 219 consecutive patients treated with extracorporeal membrane oxygenation for refractory postoperative cardiogenic shock. Ann Thorac Surg 2004;77:151-7. doi:10.1016/S00034975(03)01329-8.

[7] Listijono DR, Watson A, Pye R, Keogh AM, Kotlyar E, Spratt P, et al. Usefulness of extracorporeal membrane oxygenation for early cardiac allograft dysfunction. J Heart Lung Transplant 2011;30:783-9. doi:10.1016/j.healun.2011.01.728.

[8] Stulak JM, Dearani JA, Burkhart HM, Barnes RD, Scott PD, Schears GJ. ECMO Cannulation Controversies and Complications. Semin Cardiothorac Vasc Anesth 2009;13:176-82. doi:10.1177/1089253209347943.

[9] Conrad SA, Grier LR, Scott LK, Green R, Jordan M. Percutaneous Cannulation for Extracorporeal Membrane Oxygenation by Intensivists: A Retrospective Single-Institution Case Series*. Crit Care Med 2015;43:1010-5. doi:10.1097/CCM.0000000000000883.

[10] Bisdas T, Beutel G, Warnecke G, Hoeper MM, Kuehn C, Haverich A, et al. Vascular complications in patients undergoing femoral cannulation for extracorporeal membrane oxygenation support. Ann Thorac Surg 2011;92:626-31. doi:10.1016/j.athoracsur.2011.02.018.

[11] Foley PJ, Morris RJ, Woo EY, Acker MA, Wang GJ, Fairman RM, et al. Limb ischemia during femoral cannulation for cardiopulmonary support. J Vasc Surg 2010;52:850-3. doi:10.1016/j.jvs.2010.05.012.

[12] Kanji HD, Schulze CJ, Oreopoulos A, Lehr EJ, Wang W, MacArthur RM. Peripheral versus central cannulation for extracorporeal membrane oxygenation: a comparison of limb ischemia and transfusion requirements. Thorac Cardiovasc Surg 2010;58:459-62. doi:10.1055/s-00301250005.

[13] Vanzetto G, Akret C, Bach V, Barone G, Durand M, Chavanon O, et al. [Percutaneous extracorporeal life support in acute severe hemodynamic collapses: single centre experience in 100 consecutive patients]. Can J Cardiol 2009;25:e179-186.

[14] Wearn JT. The role of the Thebesian vessels in the circulation of the heart. J Exp Med 1928;47:293. 
[15] Ma P, Zhang Z, Song T, Yang Y, Meng G, Zhao J, et al. Combining ECMO with IABP for the Treatment of Critically III Adult Heart Failure Patients. Heart Lung Circ 2014;23:363-8. doi:10.1016/j.hlc.2013.10.081.

[16] Scheidt S, Wilner G, Mueller H, Summers D, Lesch M, Wolff G, et al. Intra-Aortic Balloon Counterpulsation in Cardiogenic Shock: Report of a Cooperative Clinical Trial. N Engl J Med 1973;288:979-84. doi:10.1056/NEJM197305102881901.

[17] Gass A, Palaniswamy C, Aronow WS, Kolte D, Khera S, Ahmad H, et al. Peripheral Venoarterial Extracorporeal Membrane Oxygenation in Combination with Intra-Aortic Balloon Counterpulsation in Patients with Cardiovascular Compromise. Cardiology 2014;129:137-43. doi:10.1159/000365138.

[18] Petroni T, Harrois A, Amour J, Lebreton G, Brechot N, Tanaka S, et al. Intra-Aortic Balloon Pump Effects on Macrocirculation and Microcirculation in Cardiogenic Shock Patients Supported by Venoarterial Extracorporeal Membrane Oxygenation*: Crit Care Med 2014;42:2075-82. doi:10.1097/CCM.0000000000000410.

[19] Bréchot N, Demondion P, Santi F, Lebreton G, Pham T, Dalakidis A, et al. Intra-aortic balloon pump protects against hydrostatic pulmonary oedema during peripheral venoarterialextracorporeal membrane oxygenation. Eur Heart J Acute Cardiovasc Care 2017:204887261771116. doi:10.1177/2048872617711169.

[20] Park TK, Yang JH, Choi S-H, Song YB, Hahn J-Y, Choi J-H, et al. Clinical impact of intra-aortic balloon pump during extracorporeal life support in patients with acute myocardial infarction complicated by cardiogenic shock. BMC Anesthesiol 2014;14:27.

[21] Lin L-Y, Liao C-W, Wang C-H, Chi N-H, Yu H-Y, Chou N-K, et al. Effects of Additional Intra-aortic Balloon Counter-Pulsation Therapy to Cardiogenic Shock Patients Supported by Extra-corporeal Membranous Oxygenation. Sci Rep 2016;6. doi:10.1038/srep23838.

[22] Jouan J, Grinda J-M, Bricourt M-O, Cholley B, Fabiani J-N. Successful left ventricular decompression following peripheral extracorporeal membrane oxygenation by percutaneous placement of a micro-axial flow pump. J Heart Lung Transplant 2010;29:135-136.

[23] Cheng A, Swartz MF, Massey HT. Impella to Unload the Left Ventricle During Peripheral Extracorporeal Membrane Oxygenation: ASAIO J 2013;59:533-6. doi:10.1097/MAT.0b013e31829f0e52.

[24] Kawashima D, Gojo S, Nishimura T, Itoda Y, Kitahori K, Motomura N, et al. Left Ventricular Mechanical Support with Impella Provides More Ventricular Unloading in Heart Failure Than Extracorporeal Membrane Oxygenation: ASAIO J 2011;57:169-76. doi:10.1097/MAT.0b013e31820e121c.

[25] Weymann A, Schmack B, Sabashnikov A, Bowles CT, Raake P, Arif R, et al. Central extracorporeal life support with left ventricular decompression for the treatment of refractory cardiogenic shock and lung failure. J Cardiothorac Surg 2014;9:60. doi:10.1186/1749-8090-9-60.

[26] Pappalardo F, Schulte C, Pieri M, Schrage B, Contri R, Soeffker G, et al. Concomitant implantation of Impella ${ }^{\circ}$ on top of veno-arterial extracorporeal membrane oxygenation may improve survival of patients with cardiogenic shock: Impella ${ }^{\circ}$ improves survival in cardiogenic shock. Eur J Heart Fail 2017;19:404-12. doi:10.1002/ejhf.668.

[27] Tepper S, Masood MF, Baltazar Garcia M, Pisani M, Ewald GA, Lasala JM, et al. Left Ventricular Unloading by Impella Device Versus Surgical Vent During Extracorporeal Life Support. Ann Thorac Surg 2017. doi:10.1016/j.athoracsur.2016.12.049.

[28] Soleimani B, Pae W. Management of left ventricular distension during peripheral extracorporeal membrane oxygenation for cardiogenic shock. Perfusion 2012;27:326-31. doi:10.1177/0267659112443722.

[29] Kitamura M, Shibuya M, Kurihara H, Akimoto T, Endo M, Koyanagi H. Effective Cross-Circulation Technique of Venoarterial Bypass for Differential Hypoxia Condition. Artif Organs 1997;21:786788. 
[30] Choi J, Kim S, Kim Y, Kim S-Y, Kim K-S, Joo S-J, et al. Application of veno-arterial-venous extracorporeal membrane oxygenation in differential hypoxia. Multidiscip Respir Med 2014;9:55. doi:10.1186/2049-6958-9-55.

[31] Extracorporeal Life Support Organization (ELSO). ELSO Guidelines for Adult Cardiac Failure v1.3 2013. https://www.elso.org/resources/guidelines.aspx.

[32] Napp LC, Kühn C, Hoeper MM, Vogel-Claussen J, Haverich A, Schäfer A, et al. Cannulation strategies for percutaneous extracorporeal membrane oxygenation in adults. Clin Res Cardiol 2016;105:283-96. doi:10.1007/s00392-015-0941-1.

[33] Saeed D, Stosik H, Islamovic M, Albert A, Kamiya H, Maxhera B, et al. Femoro-Femoral Versus Atrio-Aortic Extracorporeal Membrane Oxygenation: Selecting the Ideal Cannulation Technique: Central Versus Peripheral ECMO Cannulation. Artif Organs 2014;38:549-55. doi:10.1111/aor.12245.

[34] Park M, Mendes PV, Hirota AS, Santos EV dos, Costa ELV, Azevedo LCP. Blood flow/pump rotation ratio as an artificial lung performance monitoring tool during extracorporeal respiratory support using centrifugal pumps. Rev Bras Ter Intensiva 2015;27. doi:10.5935/0103507X.20150030.

[35] Fuhrman BP, Hernan LJ, Rotta AT, Heard C, Rosenkranz ER. Pathophysiology of cardiac extracorporeal membrane oxygenation. Artif Organs 1999;23:966-969.

[36] Otterspoor L, Smit F, van Laar T, Kesecioglu J, van Dijk D. Prolonged use of extracorporeal membrane oxygenation combined with prone positioning in patients with acute respiratory distress syndrome and invasive Aspergillosis. Perfusion 2012;27:335-7. doi:10.1177/0267659112442098.

[37] Kimmoun A, Roche S, Bridey C, Vanhuyse F, Fay R, Girerd N, et al. Prolonged prone positioning under VV-ECMO is safe and improves oxygenation and respiratory compliance. Ann Intensive Care 2015;5. doi:10.1186/s13613-015-0078-4.

[38] Kipping V, Weber-Carstens S, Lojewski C, Feldmann P, Rydlewski A, Boemke W, et al. Prone position during ECMO is safe and improves oxygenation. Int J Artif Organs 2013;36:821-32. doi:10.5301/ijao.5000254.

[39] Schmidt M, Pellegrino V, Combes A, Scheinkestel C, Cooper D, Hodgson C. Mechanical ventilation during extracorporeal membrane oxygenation. Crit Care 2014;18:203. doi:10.1186/cc13702.

[40] Aubron C, Cheng AC, Pilcher D, Leong T, Magrin G, Cooper DJ, et al. Factors associated with outcomes of patients on extracorporeal membrane oxygenation support: a 5-year cohort study. Crit Care 2013;17:R73.

[41] Lidegran MK, Mosskin M, Ringertz HG, Frenckner BP, Lindén VB. Cranial CT for Diagnosis of Intracranial Complications in Adult and Pediatric Patients During ECMO: Clinical Benefits in Diagnosis and Treatment. Acad Radiol 2007;14:62-71. doi:10.1016/j.acra.2006.10.004.

[42] Hemmila MR, Rowe SA, Boules TN, Miskulin J, McGillicuddy JW, Schuerer DJ, et al. Extracorporeal Life Support for Severe Acute Respiratory Distress Syndrome in Adults: Trans Meet Am Surg Assoc 2004;CXXII:193-205. doi:10.1097/01.sla.0000141159.90676.2d.

[43] Mateen FJ. Neurological Injury in Adults Treated With Extracorporeal Membrane Oxygenation. Arch Neurol 2011;68:1543. doi:10.1001/archneurol.2011.209.

[44] Cheng R, Hachamovitch R, Kittleson M, Patel J, Arabia F, Moriguchi J, et al. Complications of Extracorporeal Membrane Oxygenation for Treatment of Cardiogenic Shock and Cardiac Arrest: A Meta-Analysis of 1,866 Adult Patients. Ann Thorac Surg 2014;97:610-6. doi:10.1016/j.athoracsur.2013.09.008.

[45] Xie A, Phan K, Yi-Chin Tsai M, Yan TD, Forrest P. Venoarterial Extracorporeal Membrane Oxygenation for Cardiogenic Shock and Cardiac Arrest: A Meta-Analysis. J Cardiothorac Vasc Anesth 2015;29:637-45. doi:10.1053/j.jvca.2014.09.005.

[46] Avalli L, Maggioni E, Formica F, Redaelli G, Migliari M, Scanziani M, et al. Favourable survival of in-hospital compared to out-of-hospital refractory cardiac arrest patients treated with 
extracorporeal membrane oxygenation: An Italian tertiary care centre experience. Resuscitation 2012;83:579-83. doi:10.1016/j.resuscitation.2011.10.013.

[47] Chou T-H, Fang C-C, Yen Z-S, Lee C-C, Chen Y-S, Ko W-J, et al. An observational study of extracorporeal CPR for in-hospital cardiac arrest secondary to myocardial infarction. Emerg Med J 2014;31:441-7. doi:10.1136/emermed-2012-202173.

[48] Lin J-W, Wang M-J, Yu H-Y, Wang C-H, Chang W-T, Jerng J-S, et al. Comparing the survival between extracorporeal rescue and conventional resuscitation in adult in-hospital cardiac arrests: Propensity analysis of three-year data. Resuscitation 2010;81:796-803. doi:10.1016/j.resuscitation.2010.03.002.

[49] Park SB, Yang JH, Park TK, Cho YH, Sung K, Chung CR, et al. Developing a risk prediction model for survival to discharge in cardiac arrest patients who undergo extracorporeal membrane oxygenation. Int J Cardiol 2014;177:1031-5. doi:10.1016/j.ijcard.2014.09.124.

[50] Schopka S, Philipp A, Lunz D, Camboni D, Zacher R, Rupprecht L, et al. Single-Center Experience With Extracorporeal Life Support in 103 Nonpostcardiotomy Patients: EXTRACORPOREAL LIFE SUPPORT. Artif Organs 2013;37:150-6. doi:10.1111/j.1525-1594.2012.01544.x.

[51] Choi DS, Kim T, Ro YS, Ahn KO, Lee EJ, Hwang SS, et al. Extracorporeal life support and survival after out-of-hospital cardiac arrest in a nationwide registry: A propensity score-matched analysis. Resuscitation 2016;99:26-32. doi:10.1016/j.resuscitation.2015.11.013.

[52] Lamhaut L, Hutin A, Puymirat E, Jouan J, Raphalen J-H, Jouffroy R, et al. A Pre-Hospital Extracorporeal Cardio Pulmonary Resuscitation (ECPR) strategy for treatment of refractory out hospital cardiac arrest: An observational study and propensity analysis. Resuscitation 2017. doi:10.1016/j.resuscitation.2017.04.014.

[53] Sawamoto K, Bird SB, Katayama Y, Maekawa K, Uemura S, Tanno K, et al. Outcome from severe accidental hypothermia with cardiac arrest resuscitated with extracorporeal cardiopulmonary resuscitation. Am J Emerg Med 2014;32:320-4. doi:10.1016/j.ajem.2013.12.023.

[54] de Lange DW, Sikma MA, Meulenbelt J. Extracorporeal membrane oxygenation in the treatment of poisoned patients. Clin Toxicol 2013;51:385-93. doi:10.3109/15563650.2013.800876.

[55] Walpoth BH, Walpoth-Aslan BN, Mattle HP, Radanov BP, Schroth G, Schaeffler L, et al. Outcome of survivors of accidental deep hypothermia and circulatory arrest treated with extracorporeal blood warming. N Engl J Med 1997;337:1500-1505.

[56] Maggio P, Hemmila M, Haft J, Bartlett R. Extracorporeal Life Support for Massive Pulmonary Embolism: J Trauma Inj Infect Crit Care 2007;62:570-6. doi:10.1097/TA.0b013e318031cd0c.

[57] Recommandations sur les indications de l'assistance circulatoire dans le traitement des arrêts cardiaques réfractaires. Ann Fr Anesth Réanimation 2009;28:182-6. doi:10.1016/j.annfar.2008.12.011.

[58] Peberdy MA, Callaway CW, Neumar RW, Geocadin RG, Zimmerman JL, Donnino M, et al. Part 9: Post-Cardiac Arrest Care: 2010 American Heart Association Guidelines for Cardiopulmonary Resuscitation and Emergency Cardiovascular Care. Circulation 2010;122:S768-86. doi:10.1161/CIRCULATIONAHA.110.971002.

[59] de Chambrun MP, Bréchot N, Lebreton G, Schmidt M, Hekimian G, Demondion P, et al. Venoarterial extracorporeal membrane oxygenation for refractory cardiogenic shock postcardiac arrest. Intensive Care Med 2016. doi:10.1007/s00134-016-4541-y.

[60] Bougouin W, Aissaoui N, Combes A, Deye N, Lamhaut L, Jost D, et al. Post-cardiac arrest shock treated with veno-arterial extracorporeal membrane oxygenation. Resuscitation 2017;110:12632. doi:10.1016/j.resuscitation.2016.11.005.

[61] O'Gara PT, Kushner FG, Ascheim DD, Casey DE, Chung MK, de Lemos JA, et al. 2013 ACCF/AHA Guideline for the Management of ST-Elevation Myocardial Infarction: A Report of the American College of Cardiology Foundation/American Heart Association Task Force on Practice Guidelines. Circulation 2013;127:e362-425. doi:10.1161/CIR.0b013e3182742cf6.

[62] Authors/Task Force Members, McMurray JJV, Adamopoulos S, Anker SD, Auricchio A, Böhm M, et al. ESC Guidelines for the diagnosis and treatment of acute and chronic heart failure 2012: 
The Task Force for the Diagnosis and Treatment of Acute and Chronic Heart Failure 2012 of the European Society of Cardiology. Developed in collaborati. Eur J Heart Fail 2012;14:803-69. doi:10.1093/eurjhf/hfs105.

[63] Chen J-S, Ko W-J, Yu H-Y, Lai L-P, Huang S-C, Chi N-H, et al. Analysis of the outcome for patients experiencing myocardial infarction and cardiopulmonary resuscitation refractory to conventional therapies necessitating extracorporeal life support rescue*: Crit Care Med 2006;34:950-7. doi:10.1097/01.CCM.0000206103.35460.1F.

[64] Fujimoto K, Kawahito K, Yamaguchi A, Sakuragawa H, Tsuboi J, Yuri K, et al. Percutaneous extracorporeal life support for treatment of fatal mechanical complications associated with acute myocardial infarction. Artif Organs 2001;25:1000-3.

[65] Sheu J-J, Tsai T-H, Lee F-Y, Fang H-Y, Sun C-K, Leu S, et al. Early extracorporeal membrane oxygenator-assisted primary percutaneous coronary intervention improved 30-day clinical outcomes in patients with ST-segment elevation myocardial infarction complicated with profound cardiogenic shock: Crit Care Med 2010;38:1810-7. doi:10.1097/CCM.0b013e3181e8acf7.

[66] Muller G, Flecher E, Lebreton G, Luyt C-E, Trouillet J-L, Bréchot N, et al. The ENCOURAGE mortality risk score and analysis of long-term outcomes after VA-ECMO for acute myocardial infarction with cardiogenic shock. Intensive Care Med 2016;42:370-8. doi:10.1007/s00134-0164223-9.

[67] Rajagopal SK, Almond CS, Laussen PC, Rycus PT, Wypij D, Thiagarajan RR. Extracorporeal membrane oxygenation for the support of infants, children, and young adults with acute myocarditis: A review of the Extracorporeal Life Support Organization registry*: Crit Care Med 2010;38:382-7. doi:10.1097/CCM.0b013e3181bc8293.

[68] Maejima Y, Yasu T, Kubo N, Kawahito K, Omura N, Katsuki T, et al. Long-term prognosis of fulminant myocarditis rescued by percutaneous cardiopulmonary support device. Circ J 2004;68:829-833.

[69] Vieillard-Baron A. Septic cardiomyopathy. Ann Intensive Care 2011;1:1.

[70] Huang C-T, Tsai Y-J, Tsai P-R, Ko W-J. Extracorporeal membrane oxygenation resuscitation in adult patients with refractory septic shock. J Thorac Cardiovasc Surg 2013;146:1041-6. doi:10.1016/j.jtcvs.2012.08.022.

[71] Park TK, Yang JH, Jeon K, Choi S-H, Choi J-H, Gwon H-C, et al. Extracorporeal membrane oxygenation for refractory septic shock in adults. Eur J Cardiothorac Surg 2015;47:e68-74. doi:10.1093/ejcts/ezu462.

[72] Rastan AJ, Dege A, Mohr M, Doll N, Falk V, Walther T, et al. Early and late outcomes of 517 consecutive adult patients treated with extracorporeal membrane oxygenation for refractory postcardiotomy cardiogenic shock. J Thorac Cardiovasc Surg 2010;139:302-311.e1. doi:10.1016/j.jtcvs.2009.10.043.

[73] Stehlik J, Edwards LB, Kucheryavaya AY, Benden C, Christie JD, Dobbels F, et al. The Registry of the International Society for Heart and Lung Transplantation: Twenty-eighth Adult Heart Transplant Report-2011. J Heart Lung Transplant 2011;30:1078-94. doi:10.1016/j.healun.2011.08.003.

[74] Christie JD, Edwards LB, Kucheryavaya AY, Benden C, Dipchand Al, Dobbels F, et al. The Registry of the International Society for Heart and Lung Transplantation: 29th Adult Lung and HeartLung Transplant Report-2012. J Heart Lung Transplant 2012;31:1073-86. doi:10.1016/j.healun.2012.08.004.

[75] Yusen RD, Christie JD, Edwards LB, Kucheryavaya AY, Benden C, Dipchand Al, et al. The Registry of the International Society for Heart and Lung Transplantation: Thirtieth Adult Lung and HeartLung Transplant Report-2013; Focus Theme: Age. J Heart Lung Transplant 2013;32:965-78. doi:10.1016/j.healun.2013.08.007.

[76] Hartwig MG, Walczak R, Lin SS, Davis RD. Improved Survival but Marginal Allograft Function in Patients Treated With Extracorporeal Membrane Oxygenation After Lung Transplantation. Ann Thorac Surg 2012;93:366-71. doi:10.1016/j.athoracsur.2011.05.017. 
[77] Mihaljevic T, Jarrett CM, Gonzalez-Stawinski G, Smedira NG, Nowicki ER, Thuita L, et al. Mechanical circulatory support after heart transplantation. Eur J Cardiothorac Surg 2011. doi:10.1016/j.ejcts.2011.04.017.

[78] Lima EB, Cunha CR da, Barzilai VS, Ulhoa MB, Barros MR de, Moraes CS, et al. Experience of ECMO in Primary Graft Dysfunction after Orthotopic Heart Transplantation. Arq Bras Cardiol 2015. doi:10.5935/abc.20150082.

[79] Pagani FD, Lynch W, Swaniker F, Dyke DB, Bartlett R, Koelling T, et al. Extracorporeal life support to left ventricular assist device bridge to heart transplant a strategy to optimize survival and resource utilization. Circulation 1999;100:II-206.

[80] Chung JC-Y, Tsai P-R, Chou N-K, Chi N-H, Wang S-S, Ko W-J. Extracorporeal membrane oxygenation bridge to adult heart transplantation: ECMO bridge to heart transplantation. Clin Transplant 2009;24:375-80. doi:10.1111/j.1399-0012.2009.01084.x.

[81] Marasco SF, Lo C, Murphy D, Summerhayes R, Quayle M, Zimmet A, et al. Extracorporeal Life Support Bridge to Ventricular Assist Device: The Double Bridge Strategy: Thoughts and Progress. Artif Organs 2015:n/a-n/a. doi:10.1111/aor.12496.

[82] Kirklin JK, Naftel DC, Pagani FD, Kormos RL, Stevenson LW, Blume ED, et al. Sixth INTERMACS annual report: A 10,000-patient database. J Heart Lung Transplant 2014;33:555-64. doi:10.1016/j.healun.2014.04.010.

[83] Barge-Caballero E, Paniagua-Martín MJ, Marzoa-Rivas R, Campo-Pérez R, Rodríguez-Fernández JÁ, Pérez-Pérez A, et al. Usefulness of the INTERMACS Scale for predicting outcomes after urgent heart transplantation. Rev Esp Cardiol Engl Ed 2011;64:193-200.

[84] Stevenson LW, Pagani FD, Young JB, Jessup M, Miller L, Kormos RL, et al. INTERMACS Profiles of Advanced Heart Failure: The Current Picture. J Heart Lung Transplant 2009;28:535-41. doi:10.1016/j.healun.2009.02.015.

[85] Chassot P-G, Bettex D, Boegli Y, Delabays A, Ferrarri E, Iglesias J-F, et al. Anesthésie et insuffisance ventriculaire. Précis Anesth. En Chir. Card., vol. 12, 2015.

[86] Aissaoui N, El-Banayosy A, Combes A. How to wean a patient from veno-arterial extracorporeal membrane oxygenation. Intensive Care Med 2015;41:902-5. doi:10.1007/s00134-015-3663-y.

[87] Aissaoui N, Luyt C-E, Leprince P, Trouillet J-L, Léger P, Pavie A, et al. Predictors of successful extracorporeal membrane oxygenation (ECMO) weaning after assistance for refractory cardiogenic shock. Intensive Care Med 2011;37:1738-45. doi:10.1007/s00134-011-2358-2.

[88] Chen Y-S, Chao A, Yu H-Y, Ko W-J, Wu I-H, Chen RJ-C, et al. Analysis and results of prolonged resuscitation in cardiac arrest patients rescued by extracorporeal membrane oxygenation. J Am Coll Cardiol 2003;41:197-203.

[89] Sung K, Lee YT, Park PW, Park K-H, Jun T-G, Yang J-H, et al. Improved survival after cardiac arrest using emergent autopriming percutaneous cardiopulmonary support. Ann Thorac Surg 2006;82:651-6. doi:10.1016/j.athoracsur.2006.03.017.

[90] Ruttmann E, Weissenbacher A, Ulmer H, Müller L, Höfer D, Kilo J, et al. Prolonged extracorporeal membrane oxygenation-assisted support provides improved survival in hypothermic patients with cardiocirculatory arrest. J Thorac Cardiovasc Surg 2007;134:594600. doi:10.1016/j.jtcvs.2007.03.049.

[91] Chen Y-S, Yu H-Y, Huang S-C, Lin J-W, Chi N-H, Wang C-H, et al. Extracorporeal membrane oxygenation support can extend the duration of cardiopulmonary resuscitation*: Crit Care Med 2008;36:2529-35. doi:10.1097/CCM.0b013e318183f491.

[92] Le Guen M, Nicolas-Robin A, Carreira S, Raux M, Leprince P, Riou B, et al. Extracorporeal life support following out-of-hospital refractory cardiac arrest. Crit Care 2011;15:R29.

[93] Liu Y, Cheng YT, Chang JC, Chao SF, Chang BS. Extracorporeal membrane oxygenation to support prolonged conventional cardiopulmonary resuscitation in adults with cardiac arrest from acute myocardial infarction at a very low-volume centre. Interact Cardiovasc Thorac Surg 2011;12:389-93. doi:10.1510/icvts.2010.256388.

[94] Shin TG, Choi J-H, Jo IJ, Sim MS, Song HG, Jeong YK, et al. Extracorporeal cardiopulmonary resuscitation in patients with inhospital cardiac arrest: A comparison with conventional 
cardiopulmonary resuscitation*: Crit Care Med 2011;39:1-7. doi:10.1097/CCM.0b013e3181feb339.

[95] Haneya A, Philipp A, Diez C, Schopka S, Bein T, Zimmermann M, et al. A 5-year experience with cardiopulmonary resuscitation using extracorporeal life support in non-postcardiotomy patients with cardiac arrest. Resuscitation 2012;83:1331-7. doi:10.1016/j.resuscitation.2012.07.009.

[96] Wu M-Y, Lee M-Y, Lin C-C, Chang Y-S, Tsai F-C, Lin P-J. Resuscitation of non-postcardiotomy cardiogenic shock or cardiac arrest with extracorporeal life support: The role of bridging to intervention. Resuscitation 2012;83:976-81. doi:10.1016/j.resuscitation.2012.01.010.

[97] Leick J, Liebetrau C, Szardien S, Fischer-Rasokat U, Willmer M, van Linden A, et al. Door-toimplantation time of extracorporeal life support systems predicts mortality in patients with outof-hospital cardiac arrest. Clin Res Cardiol 2013;102:661-9. doi:10.1007/s00392-013-0580-3.

[98] Maekawa K, Tanno K, Hase M, Mori K, Asai Y. Extracorporeal Cardiopulmonary Resuscitation for Patients With Out-of-Hospital Cardiac Arrest of Cardiac Origin: A Propensity-Matched Study and Predictor Analysis*. Crit Care Med 2013;41:1186-96. doi:10.1097/CCM.0b013e31827ca4c8.

[99] Johnson NJ, Acker M, Hsu CH, Desai N, Vallabhajosyula P, Lazar S, et al. Extracorporeal life support as rescue strategy for out-of-hospital and emergency department cardiac arrest. Resuscitation 2014;85:1527-32. doi:10.1016/j.resuscitation.2014.08.028.

[100] Kim SJ, Jung JS, Park JH, Park JS, Hong YS, Lee SW. An optimal transition time to extracorporeal cardiopulmonary resuscitation for predicting good neurological outcome in patients with outof-hospital cardiac arrest: a propensity-matched study. Crit Care 2014;18:535.

[101] Sakamoto T, Morimura N, Nagao K, Asai Y, Yokota H, Nara S, et al. Extracorporeal cardiopulmonary resuscitation versus conventional cardiopulmonary resuscitation in adults with out-of-hospital cardiac arrest: A prospective observational study. Resuscitation 2014;85:762-8. doi:10.1016/j.resuscitation.2014.01.031.

[102] Wang C-H, Chou N-K, Becker LB, Lin J-W, Yu H-Y, Chi N-H, et al. Improved outcome of extracorporeal cardiopulmonary resuscitation for out-of-hospital cardiac arrest - A comparison with that for extracorporeal rescue for in-hospital cardiac arrest. Resuscitation 2014;85:121924. doi:10.1016/j.resuscitation.2014.06.022.

[103] Han S, Kim H, Choi H, Hong G, Lee W, Lee S, et al. Predictors of survival following extracorporeal cardiopulmonary resuscitation in patients with acute myocardial infarction-complicated refractory cardiac arrest in the emergency department: a retrospective study. J Cardiothorac Surg 2015;10:23. doi:10.1186/s13019-015-0212-2.

[104] Huang C-T, Tsai Y-J, Tsai P-R, Ko W-J. Extracorporeal membrane oxygenation resuscitation in adult patients with refractory septic shock. J Thorac Cardiovasc Surg 2013;146:1041-6. doi:10.1016/j.jtcvs.2012.08.022. 


\section{Fundings}

2 This research did not receive any specific grant from funding agencies in the public,

3 commercial, or not-for-profit sectors.

4 